\title{
Development of indicators for identifying adverse drug events in an Indian tertiary care teaching hospital
}

This article was published in the following Dove Press journal:

Drug, Healthcare and Patient Safety

29 June 2010

Number of times this article has been viewed

\author{
Rajakannan Thiyagu' \\ Surulivel R Mallayasamy' \\ Valakkathala Rajesh' \\ Varma Muralidhar ${ }^{2}$ \\ Prabhu Smitha ${ }^{3}$ \\ Vidyasagar Sudha ${ }^{2}$ \\ Bairy K Laxminarayana ${ }^{4}$ \\ 'Department of Pharmacy Practice, \\ Manipal College of Pharmaceutical \\ Sciences, Manipal University, Manipal, \\ India; ${ }^{2}$ Department of General \\ Medicine, ${ }^{3}$ Department of Skin \& \\ STD, ${ }^{4}$ Department of Pharmacology, \\ Kasturba Medical College, Manipal \\ University, Manipal, India
}

Objective: Adverse drug events (ADEs) are drug-related events which continue to pose serious challenges to the safety of patients. There are a number of ways to monitor ADEs, and the use of indictors to screen them provides an alternative method for detecting them. This method helps to assess the safety of drugs by the manual record review technique. The aim of this work was to develop a list of indicators to use in medical units of the study hospital to identify ADEs.

Setting: Tertiary care teaching hospital in India.

Method: An initial list of ADE indicators based on published literature was developed by a panel of three experts. The list of indicators was subjected to review by a Delphi panel of five members. The Delphi panel reviewed the list of valid indicators and also suggested an addition of new indicators. The final list of indicators was used to review 100 previously documented ADE case reports. The case reports were screened for the presence of any of the indicators from the list. Parameters studied included number of indicators per case report and the most used indicators. Results: From the literature, a 72 item indicator list was initially prepared which was further narrowed down to a list of 63 items. The Delphi panel conducted a review with these 63 items. At the end of review, and after addition and deletion of indicators, a 49 item indicator list was finalized. When this list of indicators was used for the review of ADE case reports, 42 indicators were identified. On average, three indicators were present in the reviewed case reports.

Conclusion: An indicator list was developed for identification of ADEs in the study setup. The relevance of this indicator list was demonstrated by the presence of these indicators in the previously documented ADE reports. This is the first study from India to report on the development of ADE indicators, which might provide an alternative method to detecting ADEs in the setup of future studies.

Keywords: adverse drug events, drug safety indicators, Delphi panel

\section{Introduction}

An adverse drug event (ADE) is defined as "an injury resulting from medical intervention related to drugs". ${ }^{1}$ ADEs continues to be a serious challenge for the safety of patients. A significant number of ADEs are preventable in nature, and therefore this represents an avoidable burden on health care. ${ }^{2}$ ADEs are monitored in a clinical setup using a number of methods like case reports, spontaneous reporting systems, intensive event recording, case-control studies, case-cohort studies, prospective cohort studies, incident reports, retrospective or concurrent chart reviews and observational studies. ${ }^{3-5}$ Each methodology has its own advantages and disadvantages. ${ }^{6}$

An indicator is a clue that helps a health care organization to identify adverse events and assess the overall harm that occurs from medical care within that organization. ${ }^{7}$ This methodology is based on identifying and addressing errors that are
Correspondence:Thiyagu Rajakannan Senior Research Fellow, Department of Pharmacy Practice, Manipal College of Pharmaceutical Sciences, Manipal University, Manipal-576104, India

Tel +91 8202922403

Fax +91 8202571998

Email thiyagur@hotmail.com 
highly associated with negative outcomes. ${ }^{8,9}$ Indicators offer an approach to standardizing error identification that may provide more consistent and accurate information than traditional error reporting systems. ${ }^{10}$ This system was also used for identification of adverse events along with traditional chart audits, incident reporting, or voluntary reporting. There are a number of reports on implementing electronic triggers to screen hospital records for the occurrence of ADEs. ${ }^{11,12}$

India is a developing country which is a member of the World Health Organization-run pharmacovigilance program. The pharmacovigilance in this country is still in its infancy. ${ }^{13}$ ADE monitoring is carried out sporadically, and studies have reported that under-reporting is common in many of the study sites. ${ }^{14-16}$ This study was carried out in a tertiary care teaching hospital in South India. The ADE monitoring program was initiated in the current setup around a decade ago, but the level of participation of clinicians in this program is low. ${ }^{17}$ It was planned to use indicators to identify ADEs in the current setup. For this purpose there was a need to develop a list of indicators specific for this setup. The present work was aimed to develop an indicator list based on available literature and modify it suitably with the help of a Delphi panel review and review of adverse event case reports.

\section{Methodology \\ Development of indicators list}

An initial list of ADE indicators was prepared based on published literature. ${ }^{7,18-23}$ These indicators were reviewed by a panel of three experts (two clinical pharmacists and a clinician). The indicators which were relevant to the study setup were selected. The indicators relevant to general medical practice were kept in the list, whereas the indicators related to other specialties like psychiatry, intensive care unit (ICU), and surgery, were deleted. The review team collectively decided on whether to keep or delete a particular indicator from the list. This exercise was carried out to condense the list, so that the Delphi panel could work on it for the development of a final set of indicators.

\section{Delphi panel review}

A Delphi panel was formed with three clinicians and two clinical pharmacists. The members evaluated the indicator list anonymously and scored it. The panel members rated each item on the list on a Likert scale which represented a score from 1 to 5 . During this review panel members were asked to suggest any additional indicators which could be added to the list. At the end of the first review, the scores were summarized and this was presented to the panel members along with their own scores. In the second review, panel members were encouraged to reassess their opinion in light of scores given by other members.
Additional indicators were added to the list for review. After the second review, the mean score for each item was calculated. The mean score of 3 and above, out of 5 , was considered as criteria for inclusion into the list. For the newly added indicators, one more review was conducted and mean scores were calculated. The final comprehensive list was divided into four categories, namely: (1) abnormal changes in clinical condition, (2) changes in patient care process, (3) drug-related alterations, (4) changes in lab investigations. (Tables 1-4)

After the preparation of a comprehensive list of indicators, they were used to screen previously identified and documented ADE case reports. A set of 100 previously documented ADE reports were randomly picked from the documented database. These adverse events were identified by clinical pharmacists from medicine wards during their rounds with clinicians. These reports contain complete details of the case which included medical history, diagnosis, lab investigations, therapy and ADE. Reports were reviewed for the presence of any indicators from the prepared list. The following four factors were then assessed: mean number of indicators per case report, commonly identified indicators, total number of identified indicators, and indicators that were not identified in any of the case reports.

\section{Results}

\section{Screening by expert panel}

From the literature, 72 indicators were selected for the list. The expert panel conducted a review of indicators. Items were added to the list based on the relevance of indicators for the internal medicine department and the utility of specific indicators. Indicators like 'hospital visit due to depression or other psychiatric illness due to drug treatment or lack of monitoring' was removed since such cases are usually presented to the psychiatry department and do not come under the general medicine department. Specific indicators like theophylline toxicity were removed because the use of theophylline is less common and its monitoring is not carried out. Indicators like toxicity of individual antiepileptic drugs such as phenytoin, carbamazepine, and sodium valproate were combined as 'drug toxicity'. An indicator on long term use of codeine and acetaminophen for pain relief resulting in broken bones was removed since such a practice of using codeine for pain relief is not common in this setup. Indicators on gastritis and upper intestinal bleeding due to many different drugs and factors were reduced to two indicators. Many indicators were recommended to be deleted since their prevalence was thought to be low for this setup. Some indicators were combined with others since they were similar. At the end of the review, the list was modified to include 63 indicators. 
Table I Indicators of abnormal change in clinical condition of patients

\begin{tabular}{|c|c|}
\hline Indicators & Cause \\
\hline Headache & Drug induced \\
\hline Over-sedation/lethargy/hypotension & Medication-related ADE \\
\hline Immobility (emboli) & Low molecular heparin \\
\hline \multirow[t]{2}{*}{ Bleeding } & Use of warfarin without monitoring INR during initiation and follow-up of therapy. \\
\hline & $\begin{array}{l}\text { Concurrent use of warfarin and an oral/topical NSAID/antibiotic/ACE inhibitors/ } \\
\text { amiodarone without monitoring the INR within I } 0 \text { days. }\end{array}$ \\
\hline Diarrhea/use of antidiarrheal & Antibiotics \\
\hline Dyspepsia or upper Gl bleed or perforation or Gl ulcer & Use of a beta-blocker/oral or topical NSAIDs/oral corticosteroids in a patient with \\
\hline \multirow[t]{3}{*}{ or anemia/use of PPIs } & a PMH or current diagnosis of peptic ulcers and/or Gl bleeding. Additional reliability \\
\hline & indicator. Use of more than one NSAID for more than two weeks without \\
\hline & protective agents like $\mathrm{H}_{2}$ receptor antagonists or PPIs. \\
\hline GI disturbance or Gl bleed & Long-term use of ferrous sulphate without monitoring hemoglobin \\
\hline Melena & Drug induced GI Ulcer \\
\hline Vomiting, nausea/use of antiemetics & Drug induced \\
\hline Loss of seizure control or seizure activity & $\begin{array}{l}\text { Use of lamotrigine/carbamazepine/phenytoin/valproic acid without drug level } \\
\text { monitoring at least every } 6 \text { months. Use of antibiotics. }\end{array}$ \\
\hline Tremor & Drug induced \\
\hline Acute renal failure and/or renal insufficiency & $\begin{array}{l}\text { Use of an ACE inhibitor (eg, captopril, enalapril, etc). BUN/serum creatinine not } \\
\text { done at initiation of therapy and at least every } 3 \text { months thereafter. Use of NSAID } \\
\text { for } 3 \text { months. Use of Lithium. }\end{array}$ \\
\hline Acute urinary retention & $\begin{array}{l}\text { Diagnosis/history of bladder atony due to diabetes. Use of imipramine. Diagnosis } \\
\text { of } \mathrm{BPH} \text { and use of an anticholinergic agent. }\end{array}$ \\
\hline Acute respiratory failure & $\begin{array}{l}\text { History/diagnosis of severe COPD. Use of a medium- to long- acting } \\
\text { benzodiazepine. }\end{array}$ \\
\hline Asthma exacerbation and/or status asthmaticus and/or & Diagnosis of asthma. Use of a bronchodilator. No use of a maintenance \\
\hline ER visit/hospitalization due to asthma & corticosteroid (eg, beclomethasone, etc). \\
\hline Hospital visit due to asthma symptoms & $\begin{array}{l}\text { Use of an inhaled short-acting bronchodilator more than once daily or at night } \\
\text { in an asthmatic patient with no regular inhaled 'preventer' therapy } \\
\text { (corticosteroid, cromoglicate, or nedocromil) }\end{array}$ \\
\hline \multirow[t]{3}{*}{ ER visit/hospitalization due to hyperthyroidism } & Use of a thyroid or antithyroid agent (eg, levothyroxine, propylthiouracil, etc). \\
\hline & $\mathrm{T}_{4} / \mathrm{TSH}$ not done within 6 weeks after initiation of therapy and at least every \\
\hline & 12 months thereafter. \\
\hline ER visit/hospitalization due to hypothyroidism & Lithium use for at least 6 months. TSH not done at least every 6 months. \\
\hline Oral thrush/dysphonia/oral candidiasis & Use of an inhaled steroid by metered dose inhaler without usage of a spacer device \\
\hline Edema & Chronic use of amlodipine \\
\hline Skin rashes/angioedema/Steven Johnson syndrome/TEN & Drug induced \\
\hline Pyrexia & Drug induced \\
\hline
\end{tabular}

Abbreviations: GI, gastrointestinal; PPIs, proton pump inhibitors; ER visit, emergency room visit; TEN, toxic epidermal necrolysis; ADE, adverse drug event; INR, international normalized ratio; NSAID, nonsteroidal anti-inflammatory drug; ACE inhibitors, angiotensin-converting enzyme inhibitors; PMH, postmenopasusal hormone; BUN, blood urea nitrogen; BPH, benign prostate hyperplasia; COPD, chronic obstructive pulmonary disease; TSH, thyroid-stimulating hormone.

\section{Delphi panel review}

The Delphi panel reviewed the indicator list for its utility. Five reviewers independently reviewed the list and rated them on a scale of 1 to 5 . At the end of the first review, 22 out of 63 items in the list were rated less than 3 points and were subsequently eliminated. Eight new indicators were suggested by the members of Delphi panel. In the second review a total of 71 items were included in the list. The panel members were asked to rate all of the items. At the end of the second review, a total of 49 indicators received scores above 3 . The results were again presented to the panel members with their scores against the scores of other team members for the third review. The third review did not alter the scores, 49 were rated above 3 points, and were included in the list.

\section{Assessment of documented adverse event reports}

A total of 42 indicators were identified in previous ADE case reports. Each reviewed case report had an average of three indicators from the list. Seven indicators could not be identified in any of the reported case records. Indicators which were most frequently identified from the reports were studied (Table 5). Abrupt drug withdrawal was the most common indicator identified in the reports, followed by repeat requests for laboratory tests, and use of antihistamine/steroids for the management of drug allergies. Drug induced pyrexia, edema, raised serum creatinine, and tremors were among the least identified indicators in reviewed reports. 
Table 2 Indicators of change in patient care process

\begin{tabular}{ll}
\hline Indicators & Cause \\
\hline $\begin{array}{l}\text { Abrupt withdrawal of medication } \\
\text { Intubation/re-intubation }\end{array}$ & Any ADE \\
ER visit/hospitalization due to congestive heart failure & Related ADE/drug induced respiratory depress \\
& Use of a calcium channel blocker (eg, diltiazem, etc). Use of beta \\
blockers. Oral/topical NSAID use for at least 3 months. & Drug induced hematological disorder \\
Use of blood products & History/diagnosis of diabetes. Use of insulin/oral hypoglycemics. \\
ER visit/hospitalization due to extreme hypoglycemia & Use of a $\beta$-adrenergic blocking agent (eg, propranolol, nadolol). \\
& Use of fluroquinolones. \\
ER visit/hospitalization due to worsening renal impairment & Diagnosis and/or history of kidney disease. Use of tetracycline. \\
and/or acute renal failure and/or renal insufficiency & Use of a select urinary anti-infective agent (nalidixic acid, \\
Dose reduction & nitrofurantoin, or methenamine complexes). \\
Admission to dialysis unit & Related ADE \\
Emergency visit/admission & Drug-induced ARF \\
Readmission to ICU & Drug-induced complications \\
\hline
\end{tabular}

Abbreviations: ER, emergency room; ICU, intensive care unit; ADE, adverse drug event; NSAID, nonsteroidal anti-inflammatory drug; ARF, acute renal failure.

\section{Discussion}

This report describes the development of ADE indicators in the current setup. This study used a team of clinicians and pharmacists to review the developed ADE indicators. The Delphi technique, which has been used in a number of previous studies, was used as a method of assessing the developed indicator list.

An initial list of 71 indicators selected from the literature was considered unmanageable, and after the Delphi panel review, the number of indicators was reduced to 49 . In a study by Matlow et al on the development of trigger tools for pediatrics, they reported that 94 indicators were initially selected by a review committee. This list was considered as not practical for routine use, and was subsequently reduced to a manageable list of 40 indicators. ${ }^{19}$ An indicator list containing a reasonably limited number of items is preferable since it reduces the burden on case record reviewers.

Abrupt withdrawal of drugs was identified most frequently as an indicator in the records. Since this is the first step in management of any drug-related adverse event, it could be found in many of the previously documented adverse event reports. Another commonly identified indicator was frequent requests for a specific lab investigation. Repeat requests for a particular investigation signifies a certain level of complication in the management of the patient's condition, and might be associated with drug-related adverse events.

The indicator list was classified under four major categories: abnormal clinical changes, change in patient care, laboratory investigation-related, and drug/antidote-related. Among these four classes of indicators abnormal clinical changes included 22 indicators. This showed the preference of reviewers for the indicators which can identify adverse events based on the data available from patient progress charts and follow-up. Changes in patient care and lab investigations were the other important group of indicators considered for identifying ADEs (10 each). In contrast to a study published by Handler et al in which the medication concentration signals were considered as important, abnormal clinical changes were considered as important indicators in this study. ${ }^{24}$ In this study, even when toxicity was suspected for a drug, estimation of drug levels was not carried

Table 3 Indicators of drug-related alterations

\begin{tabular}{|c|c|}
\hline Indicators & Cause \\
\hline Use of antihistamines & Drug allergy \\
\hline Digoxin toxicity & $\begin{array}{l}\text { Concurrent use of digoxin and a potassium-sparing diuretic or potassium } \\
\text { supplements without monitoring digoxin levels. Addition of amiodarone/ } \\
\text { verapamil to a patient on digoxin without reducing the digoxin dosage }\end{array}$ \\
\hline Vitamin $\mathrm{K}$ & Bleeding/over usage of anticoagulant \\
\hline Use of laxative & Drug induced (antibiotics, opioids, amlodipine, amiodarone) \\
\hline Use of K-bind & Potassium toxicity \\
\hline $\begin{array}{l}\text { Aminoglycoside toxicity (acute renal failure and/or renal insufficiency } \\
\text { and/or vestibular damage and/or auditory damage) }\end{array}$ & $\begin{array}{l}\text { Use of an aminoglycoside. Serum creatinine not done before and after } \\
\text { therapy (and if therapy longer than } 7 \text { days, not done at least every } \\
7 \text { days). At least one drug level not done. }\end{array}$ \\
\hline Electrolyte/nutrient supplementation & Drug induced imbalances \\
\hline
\end{tabular}


Table 4 Indicators of lab investigation

\begin{tabular}{|c|c|}
\hline Indicators & Cause \\
\hline Frequent ECG request & Drug induced arrhythmias \\
\hline Blood dyscrasias & $\begin{array}{l}\text { Concurrent use of trimethoprim/sulfamethoxazole and methotrexate. Use } \\
\text { of carbamazepine, ticlopidine. WBC/platelets/CBC not done at least every } \\
4 \text { weeks. }\end{array}$ \\
\hline Major and/or minor hemorrhagic event, INR > 6, elevated APTT & $\begin{array}{l}\text { Use of IV heparin, warfarin. PTT not done at least every day. } \\
\text { Use of aspirin/clopidogrel/warfarin. }\end{array}$ \\
\hline Abnormal liver function tests or clinical jaundice & $\begin{array}{l}\text { Use of a statin without baseline monitoring of liver function and subsequent } \\
\text { monitoring at } 6 \text { monthly intervals. Use of pioglitazone. } \\
\text { No baseline and follow up LFTs for every month for first } 8 \text { months. }\end{array}$ \\
\hline Abnormal LFT & $\begin{array}{l}\text { Drug induced (statins, pioglitazone, isoniazid, rifampicin, pyrazinamide). LFTs } \\
\text { not done at baseline and follow up. }\end{array}$ \\
\hline $\begin{array}{l}\text { Hyponatremia and/or excessive water retention and/or } \\
\text { syndrome of inappropriate antidiuretic hormone (SIADH) }\end{array}$ & $\begin{array}{l}\text { Use of carbamazepine. Electrolytes/CBC not done before therapy initiated, at } \\
\text { least weekly during the first month of therapy, at least monthly during the next } \\
5 \text { months of therapy, and at least every } 6 \text { months thereafter. Thyroxine use. }\end{array}$ \\
\hline Electrolyte imbalance $\mathrm{K}, \mathrm{Na}, \mathrm{Cl}, \mathrm{Ca}, \mathrm{K}$ & $\begin{array}{l}\text { Drug induced (diuretics, ACE inhibitors, potassium supplements). No } \\
\text { electrolyte monitoring at the frequency of } 10 \text { days to a few months. }\end{array}$ \\
\hline Elevated BUN, SCr & Drug induced ARF \\
\hline Raised serum creatinine & $\begin{array}{l}\text { Use of an oral/topical NSAID for more than } 3 \text { months without monitoring } \\
\text { serum creatinine at least every } 3 \text { months. }\end{array}$ \\
\hline Repeated request for lab assessment of any parameter & Drug induced \\
\hline
\end{tabular}

Abbreviations: ECG, electrocardiography; INR, international normalized ratio; APTT, activated partial thromboplastin time; LFTs, liver function tests; SIADH, syndrome of inappropriate antidiuretic hormone hypersecretion; BUN, blood urea nitrogen; SCr, serum creatinine; WBC, white blood cell count; CBC, complete blood count; IV, intravenous; PTT, partial thromboplastin time; ACE inhibitors, angiotensin-converting enzyme inhibitors; ARF, acute renal failure; NSAID, nonsteroidal anti-inflammatory drug.

out routinely because of economic considerations, and clinicians mostly rely on clinical signs and symptoms to assess toxicity.

Morris and Cantril validated drug-related morbidity indicators developed in the United States and United Kingdom, and studied differences between the two setups. They reported that indicators used in the USA lacked relevance to the UK. They attributed this to the difference in clinical practice and philosophical view points of professional practice. But they concluded that if suitable validation processes can be developed, indicators from one setup can act as a starting point for another setup..$^{22}$ The current work used indicators reported from various studies and attempted to validate such indicators for the study setup. This exercise gave insight into the viewpoints of health care professionals in the study center. The methodology of using specific triggers or indicators offers flexibility in using this system for a variety of health care systems. The indicators can be modified suitably according to individual setup. ${ }^{7}$ Several institutions have used this approach in their setup and have reduced harm up to $50 \%$. Even though this method itself may not result in improvement in prevention of adverse events concerned, it provides a good platform for any organization which attempts to reduce adverse events. Record review using indicators might provide a better chance of detecting ADEs compared with many other commonly

Table 5 Most used indicators

\begin{tabular}{lll}
\hline Indicators & Cause & $\begin{array}{c}\text { No. of times indicator } \\
\text { identified in the case } \\
\text { review (I00 cases) }\end{array}$ \\
\hline $\begin{array}{l}\text { Abrupt withdrawal of medication } \\
\text { Repeated request for lab assessment of any parameter }\end{array}$ & Any ADE \\
Use of antihistamines & Drug induced \\
Skin rashes/angioedema/Steven Johnson syndrome/TEN & Drug allergy \\
Emergency visit/admission & Drug induced \\
Electrolyte imbalance K, Na, Cl, Ca, K & Drug induced complications \\
& Drug induced (diuretics, ACE inhibitors, potassium \\
Electrolyte/nutrient supplementation & supplements). No electrolyte monitoring \\
Dose reduction & at the frequency of I0 days to a few months. \\
Frequent ECG request & Drug induced imbalances \\
Vomiting, nausea/use of antiemetics & Related to ADE \\
\hline
\end{tabular}

Abbreviations: TEN, toxic epidermal necrolysis; ECG, electrocardiography; ADE, adverse drug event; ACE, angiotensin converting enzyme. 
used methods like voluntary reporting, intensive monitoring, and reporting of summary data. Use of this technique is also more economical when compared to other approaches. There are few limitations in this study which need to be considered. Even though indicators developed for one setup could be adopted for another setup, indicators adopted from a predominantly Western setup may not have relevance in the Indian setting. Unless the indicators are assessed by using them in the record review, the list might not reflect the useful indicators relevant for the current setup. Further validation is needed for this indicator list by actually using it for adverse event screening from the medical records.

\section{Conclusion}

The current work resulted in the development of an indicator list for identification of adverse events in the current setup. The list was prepared using the expert review and Delphi panel review. The final list contained a total of 49 indicators. The relevance of this indicator list was demonstrated by the presence of these indicators in the previously documented ADE case reports. This is the first study from India to report on the development of indicators, and this might provide an alternative method to detect ADEs in the studied health care setting.

\section{Acknowledgments}

The first author acknowledges the Indian Council of Medical Research for the fellowship support. The authors would like to acknowledge all health care professional of Kasturba Hospital, Manipal University and staff of Department of Pharmacy Practice for the support and encouragement extended for this work.

\section{Disclosure}

The authors report no conflicts of interest in this work.

\section{References}

1. Bates DW, Cullen D, Laird N, et al. Incidence of adverse drug events and potential adverse drug events: implications for prevention. JAMA. 1995;274:29-34.

2. Bates DW, Spell N, Cullen DJ, et al. The costs of adverse drug events in hospitalized patients. JAMA. 1997;227:307-311.

3. Brennan TA, Leape LL, Laird N, et al. Incidence of adverse events and negligence in hospitalized patients: results from the Harvard Medical Practice Study I. N Engl J Med. 1991;324:370-376.

Drug, Healthcare and Patient Safety

\section{Publish your work in this journal}

Drug, Healthcare and Patient Safety is an international, peer-reviewed open-access journal exploring patient safety issues in the healthcare continuum from diagnostic and screening interventions through to treatment, drug therapy and surgery. The journal is characterized by the rapid reporting of reviews, original research, clinical, epidemiological and
4. Edwards IR, Biriell C. Harmonization in pharmacovigilance. Drug Saf. 1994;10:93-102.

5. Brewer T, Colditz GA. Post marketing surveillance and adverse drug reactions: current perspectives and future needs. JAMA. 1999;281:824-829.

6. Palaian S, Mishra P, Shankar PR, Dubey AK, Bista D, Almeida R. Safety monitoring of drugs - where do we stand? Kathmandu Univ Med J. 2006; 4(13):119-127.

7. Institute for Healthcare Improvement. Global Trigger Tool Kit version 6, [January 2005]. Available from: http://www.ihi.org/NR/ rdonlyres/E44B4920-3E5B-4739-97618E3A7168AA0E/2438/Global TriggerToolKit6.pdf. Accessed May 13, 2005.

8. Suzanne CB. Using trigger tools to enhance patient safety. AORN J. 2005;82(1):115-116.

9. Jick H. Drugs - remarkably toxic. N Engl J Med. 1974;291:824-828.

10. Resar RK, Rozich JD, Classen D. Methodology and rationale for the measurement of harm with trigger tools. Qual Saf Health Care. 2003; 12 Suppl 2:ii39-ii45.

11. Classen DC, Pestotnik SL, Evans RS, et al. Description of a computerized adverse drug event monitor using a hospital information system. Hosp Pharm. 1992;27:774-783.

12. Szekendi MK, Sullivan C, Bobb A, et al. Active surveillance using electronic triggers to detect adverse events in hospitalized patients. Qual Saf Health Care. 2006;15:184-190.

13. Regal B. Finally a pharmacovigilant India. Uppsala Rep. 2004;25:7-8.

14. Hazell, Lorna S, Saad AW. Under-reporting of adverse drug reactions: a systematic review. Drug Saf. 2006;29(5):385-396.

15. Ramesh M, Pandit J, Parthasarathi G. Adverse drug reactions in a South Indian hospital - their severity and cost involved. Pharmacoepidemiol Drug Saf. 2003;12(8):687-692.

16. Arulmani R, Rajendran SD, Suresh B. Adverse drug reaction monitoring in a secondary care hospital in South India. Br J Clin Pharmacol. 2008;65(2):210-216.

17. Jose J, Rao PG. Pattern of adverse drug reactions notified by spontaneous reporting in an Indian tertiary care teaching hospital. Pharmacol Res. 2006;54(3):226-233.

18. Takata GS, Mason W, Taketomo C, Logsdon T, Sharek PJ. Development, testing and findings of a pediatric-focused trigger tool to identify medication-related harm in US children's hospitals. Pediatrics. 2008;121(4):e927-e935.

19. Matlow A, Flintoft V, Orrbine E, et al. The development of the Canadian paediatric trigger tool for identifying potential adverse events. Healthc $Q$. 2005;8:90-93.

20. Wet DC, Bowie P. The preliminary development and testing of a global trigger tool to detect error and patient harm in primary care records. Postgrad Med J. 2009;85(1002):176-180.

21. Szekendi MK, Sullivan C, Bobb A, et al. Active surveillance using electronic triggers to detect adverse events in hospitalized patients. Qual Saf Health Care. 2006;15(3):184-190.

22. Caroline M, Judy C. Preventable drug-related morbidity indicators in the U.S. and U.K. J Managed Care Pharm. 2002;5(8):372-377.

23. Morris CJ, Cantrill JA, Hepler CD, Noyce PR. Preventing drug-related morbidity - determining valid indicators. Int J Qual Health Care. 2002;14(3):183-198.

24. Steven MH, Joseph TH, Subashan P, Yazan FR. Consensus list of signals to detect potential adverse drug reactions in nursing homes. J Am Geriatr Soc. 2008;56(5):808-815.

post-marketing surveillance studies, risk management, health literacy and educational programs across all areas of healthcare delivery. The manuscript management system is completely online and includes a very quick and fair peer-review system. Visit http://www.dovepress.com/ testimonials.php to read real quotes from published authors. 